Marinenko V., Davydenko B.

\title{
DEVELOPMENT OF A METHODOLOGY FOR DETERMINING HEAT TRANSFER COEFFICIENTS UNDER THE EXISTENCE OF VARIOUS BOILING MODES ON A FINNED WALL
}

The object of research is the computational-experimental method of determining and identifying the heat transfer coefficients on the finned wall under the conditions of coexistence of different modes of boiling water that is forced to move. The peculiarity of cooling finned surfaces during boiling is that boiling is carried out on a non-isothermal surface. In this regard, the surface elements - «fin-wall», in the General case, can simultaneously coexist convective heat transfer, bubble, transient and film boiling. One of the problems that needs to be solved is the substantiation and development of a new method for determining the distribution of heat transfer coefficients on the surface of the fin during the coexistence of different boiling regimes on the finned wall.

Most methods of calculating heat transfer on finned surfaces are based on the assumption that the heat transfer coefficient at a given point of the non-isothermal surface is a function of only the temperature pressure between the surface and the liquid at this point. Experimental studies of heat transfer on the finned wall were carried out to test the method of calculation of heat transfer coefficients. The calculation part of the proposed method is based on the numerical method of determining the temperature field in the system «fin-wall» with a constant supply of heat from the smooth wall. Transferring, from both sides, to heat the heat flow - permanently, with given geometric dimensions, cooling, and efficiency of heat conduction material - fins to rotate the heat transfer.

The main stages of realization of computational-experimental technique are given in the work. Unlike most of the known methods for solving inverse problems, the proposed method, based on the use of three-diagonal matrix algorithm, makes it possible not to apply an iterative process to determine the heat transfer coefficients on the surfaces of the fins, which provides a quick result with a higher accuracy.

Keywords: finned wall, heat transfer coefficient, boiling modes, surface element - «fin-wall», numerical method, temperature field determination.

Received date: 29.04 .2020

Accepted date: 03.06 .2020

Published date: 31.10 .2020
Copyright (C) 2020, Marinenko V., Davydenko B. This is an open access article under the CC BY license (http://creativecommons.org/licenses/by/4.0)

\section{Introduction}

Currently, in technology, the ribbing of surfaces is increasingly used, cooled by a boiling liquid. Practice shows that in this case the heat flux entering the surface carries the fins, dissipated by the finned wall. The density of the heat flux supplied can significantly exceed the first critical density of the heat flux during boiling on isothermal surfaces. This circumstance makes the method of cooling finned surfaces with a boiling liquid promising in many branches of technology.

A feature of cooling the finned surfaces during boiling is that boiling occurs on a non-isothermal surface. In this regard, on the surface elements - «fin-wall», in the general case, convection heat exchange, bubble, transition and film boiling can simultaneously coexist. The first attempt to predict the heat transfer coefficient from a fin under conditions of boiling water is shown in [1]. Methods for solving problems of heat conductivity for a fin under conditions of liquid boiling in a large volume in a one-dimensional formulation are presented in [2-4]. The problem in a two-dimensional setting was considered in $[5,6]$. Most of the methods for thermal design of finned surfaces are based on the assumption that the heat transfer coefficient $\alpha$ at a given point on a non-isothermal surface is only a function of the difference between the temperature of the fin surface $t_{w}$ and the saturation temperature $t_{\text {sut }}$. According to [5, 7], the dependence of the heat transfer coefficient $\alpha$ on $\vartheta=t_{w}-t_{\text {sut }}$ during boiling of water in the intercostal space under conditions of a large volume has the form:

$$
\alpha(\vartheta)= \begin{cases}1169.61 \cdot \vartheta^{1 / 3}, & 0 \leq \vartheta<5 \mathrm{~K} ; \\ 80 \cdot \vartheta^{2}, & 5 \mathrm{~K} \leq \vartheta<25 \mathrm{~K} ; \\ 7.8125 \cdot 10^{8} \cdot \vartheta^{-3}, & 25 \mathrm{~K} \leq \vartheta<146 \mathrm{~K} \\ 251.033, & \vartheta \geq 146 \mathrm{~K} .\end{cases}
$$

At present, solutions of inverse problems of thermal conductivity are widely used to determine the heat transfer coefficients and nonlinear thermophysical characteristics from the experimentally determined temperature on the surface or inside the material $[8,9]$. Thus, the object of research is a computational-experimental method for determining and identifying the heat transfer coefficients on a finned wall 
in conditions of coexistence of different modes of boiling water, it is forced to move. And the aim of research is to develop a reliable algorithm for determining the heat transfer coefficients on the surfaces of the fins based on the results of measuring the temperature on the surface of the fin symmetry, which does not require the use of the iteration method.

\section{Methods of research}

In this paper, let's propose a computational and experimental method for determining and identifying the heat transfer coefficients on a finned wall under conditions of coexistence of different modes of boiling of water, it is forced to move.

To refine the technique, experimental studies of heat transfer on the finned wall were carried out. The layout of thermocouples along the height of the fins is shown in Fig. 1. Such an arrangement of thermocouples is made on the assumption that the temperature distribution along the height of each fin is the same under a steady-state heat transfer regime. The experimental setup is shown in Fig. 2.

The calculation part of the proposed method is based on the numerical method of determining the temperature field in the system «fin-wall» with a constant supply of heat from the smooth wall, Fig. 3.

An analytical method for determining the temperature field for the average heat transfer coefficients on the surface of the «fin-wall» element is given in [10], and a numerical method in [11].

Heat transfer through a finned wall element is considered, Fig. 3, located between two intersections, which are normal to the load-bearing wall. One of the sections passes through the middle of the intercostal canals, and the other through the middle of the fin. It is assumed that the indicated sections are adiabatic surfaces. It is assumed that on the heating side, the heat flux density is constant and, given the geometric dimensions, cooling conditions and the thermal conductivity of the fin material, heat transfer is improved.

The temperature field of the considered area is described by the equation:

$$
\frac{\partial^{2} T}{\partial x^{2}}+\frac{\partial^{2} T}{\partial y^{2}}=0
$$

with boundary conditions:

$$
\begin{aligned}
& y=0 ; 0 \leq x \leq L+\delta_{p}:-\lambda \frac{\partial T}{\partial y}=q_{f} \\
& y=\delta_{c} ; 0 \leq x \leq L:-\lambda \frac{\partial T}{\partial y}=\alpha_{c}\left(T-T_{\infty}\right), \\
& y=\delta_{c}+h ; L \leq x \leq L+\delta_{p}: \frac{\partial T}{\partial y}=0 \\
& x=0 ; 0 \leq y \leq \delta_{c}: \frac{\partial T}{\partial x}=0, \\
& x=L+\delta_{p} ; 0 \leq y \leq \delta_{c}+h: \frac{\partial T}{\partial x}=0
\end{aligned}
$$

$$
x=L ; \delta_{c} \leq y \leq \delta_{c}+h: \lambda \frac{\partial T}{\partial x}=\alpha_{p}\left(T-T_{\infty}\right),
$$

where $\alpha_{c}=\alpha_{c}(x)$ - distribution of heat transfer coefficients over the wall surface; $\alpha_{p}=\alpha_{p}(y)$ - distribution of heat transfer coefficients along the fin surface.

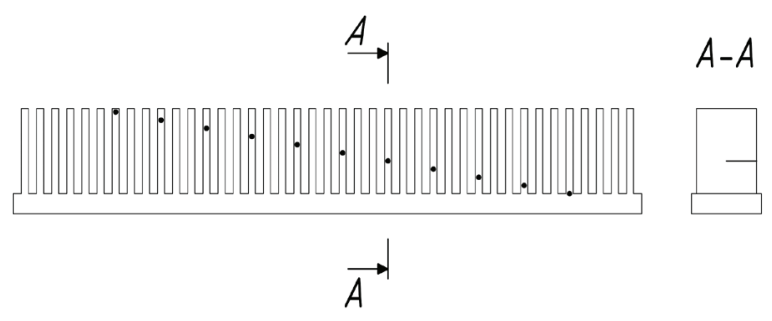

Fig. 1. Layout of thermocouples in a finned wall

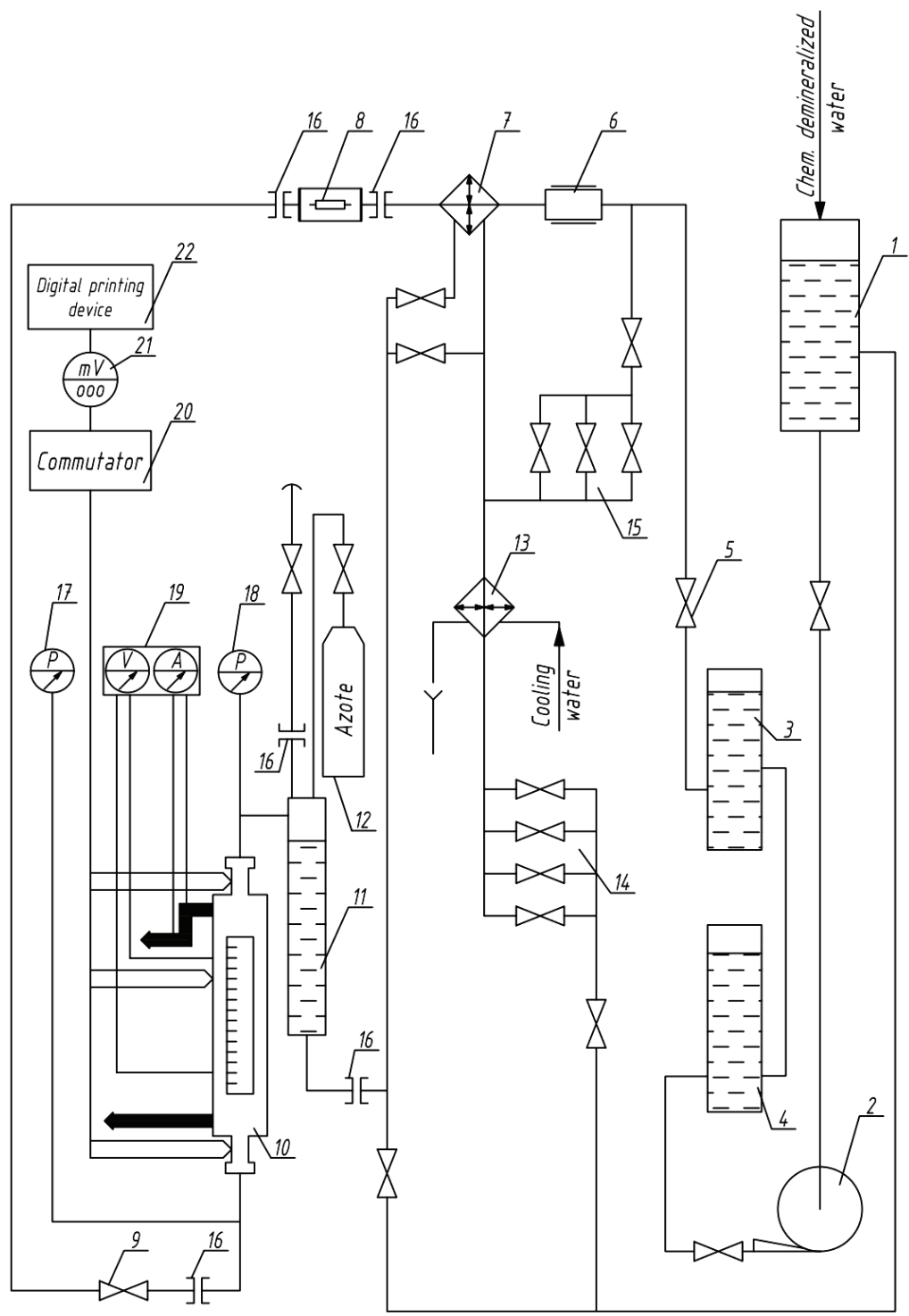

Fig. 2. Diagram of the experimental device:

1 - water tank; 2 - centrifugal pump; 3, 4 - buffer tanks; 5, 9 - throttle valve; 6 - turbine flow sensor; 7 - heat exchanger; 8 - electric heater; 10 - work area; 11 - damper container; 12 - nitrogen cylinder; 13 - refrigerator; 14 - comb of throttling valves; 15 - comb of regulating valves; 16 - insulating flanges;

17, 18 - class 0.16 manometer (USSR); 19 - point millivoltmeter M1108 class 0.2 (USSR); 20 - commutator Ф240/1 (USSR); 21 - digital voltmeter Щ68000 (USSR); 22 - digital printing device Щ6800K (US5R) 

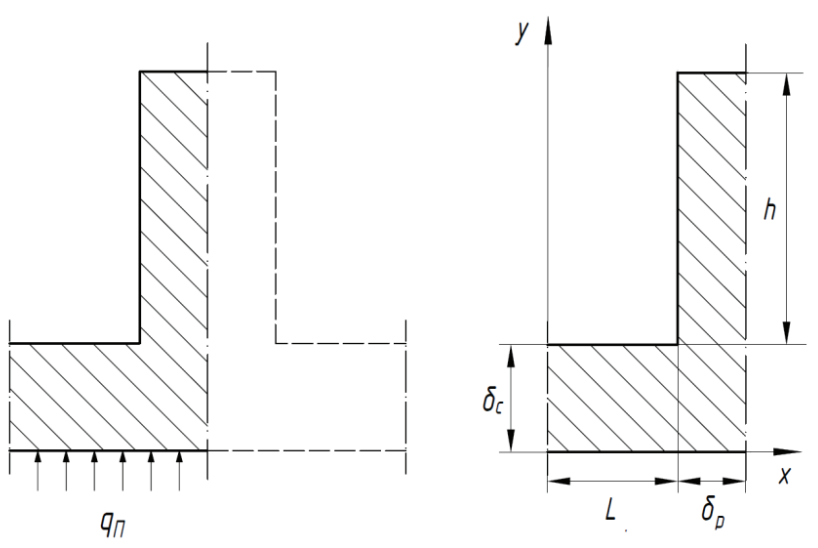

Fig. 3. Element of the finned surface - «fin-wall»

With the given geometric dimensions of the finned wall, known values of the coolant temperature $T_{\infty}$, thermal conductivity coefficient $\lambda$, heat flux density, which supplied to the wall $q_{f}$ and with known functions $\alpha_{c}(x)$; $\alpha_{p}(y)$ equation (2) with boundary conditions (3)-(8) has a unique solution that can be found by a numerical method. But in the task under consideration, the function $\alpha_{p}(y)$ must be defined. Therefore, instead of condition (8), the condition is set:

$$
x=L+\delta_{p} ; \delta_{c} \leq y \leq \delta_{c}+h: T=T_{\exp }(y),
$$

where $T_{\exp }(y)$ - experimentally determined temperature distribution over the adiabatic plane passing $0 \leq y \leq \delta_{c}+h$ through the middle of the fin $\delta_{c} \leq y \leq \delta_{c}+h$.

Thus, instead of the heat transfer condition on the fin surface (8), two boundary conditions (7) and (9) are set at $x=L+\delta_{p}$. In this case, condition (7) refers to the entire plane of symmetry, and condition (9) - only to its part.

The problem in the above formulation refers to the inverse heat conduction problems. The finite difference method is used to solve it. For this in the computational domain $0 \leq x \leq L+\delta_{p} ; 0 \leq y \leq \delta_{c}+h$ a uniform rectangular mesh is constructed with a step $h_{x}=\left(L+\delta_{p}\right) / N$ along the $0 X$ axis and with a step $h_{y}=\left(\delta_{c}+h\right) / M$ along the $0 Y$ axis $(M, N$ is the number of steps along the $0 Y$ and $0 X$ axes, respectively). In the centers of the rectangular mesh elements, nodes are located, to which the discrete temperature values $T_{i, j}$ belong. Thermal conductivity equations (2) are approximated by finite differences:

$$
\frac{T_{i+1, j}-2 T_{i, j}+T_{i-1, j}}{h_{y}^{2}}+\frac{T_{i, j+1}-2 T_{i, j}+T_{i, j-1}}{h_{x}^{2}}=0,
$$

where $i, j-$ mesh node numbers along the $0 Y$ and $0 X$ axes, respectively. After transformations, it is written as:

$$
T_{i, j+1}+\gamma \cdot T_{i+1, j}+\eta \cdot T_{i, j}+\gamma \cdot T_{i-1, j}+T_{i, j-1}=0,
$$

where $\gamma=h_{x}^{2} / h_{y}^{2} ; \eta=-2(\gamma+1)$.

To solve the system of equations (10), it is expedient to divide the computational domain into three characteristic sections. Section 1 includes that part of the wall from which heat transfer to the coolant occurs. It contains grid nodes with numbers:
$1 \leq i \leq i_{c} ; 1 \leq j \leq j_{c}$,

where $i_{c}$ - numbers of the limit grid nodes located closer to the outer surface of the wall, which is in contact with the coolant; $j_{c}$ - numbers of grid nodes corresponding to the coordinate $x=L-h_{x} / 2$. Section 2 contains mesh nodes related to the fin area. The numbers of the grid nodes located in section 2 correspond to the values: $i_{c}+1 \leq i \leq M ; j_{c}+1 \leq j \leq N$. Section 3 includes a part of the wall located under the fin. This section contains nodes with numbers $1 \leq i \leq i_{c} ; j_{c}+1 \leq j \leq N$.

In accordance with the above notation for the limiting grid nodes, the finite-difference approximation of the boundary conditions (3)-(7), (9) consists:

$$
\begin{aligned}
& i=1 ; 1 \leq j \leq N: T_{0, j}=T_{1, j}+\frac{q_{f} h_{y}}{\lambda}, \\
& i=i_{c} ; 1 \leq j \leq j_{c}:-\lambda \frac{T_{i_{c}+1, j}-T_{i_{c}, j}}{h_{y}}=\alpha_{i_{c}, j}\left(\frac{T_{i_{c}+1, j}+T_{i_{c}, j}}{2}-T_{\infty}\right), \\
& i=M ; j_{c}+1 \leq j \leq N: T_{M, j}=T_{M+1, j}, \\
& j=1 ; 1 \leq i \leq i_{c}: T_{i, 0}=T_{i, 1}, \\
& j=N ; 1 \leq i \leq M: T_{i, N+1}=T_{i, N}, \\
& j=N ; i_{c}+1 \leq i \leq M: \frac{T_{i, N}+T_{i, N+1}}{2}=T_{\exp , i} .
\end{aligned}
$$

On the surface of the fin, the boundary conditions are not defined, but conditionally on this surface, one can accept:

$$
j=j_{c}+1 ; i_{c}+1 \leq i \leq M: \frac{T_{i, j_{c}}+T_{i, j_{c}+1}}{2}=T_{w, i}
$$

where $T_{w, i}$ - the unknown discrete values of the fin surface temperature to be determined.

The solution of the system of difference equations (10) begins with section 1 , which refers to the section of the wall outside the fin. In this section, equations (10), compiled for nodes with numbers $i=1$, are written taking into account the boundary conditions (11). For nodes with numbers $i=i_{c}, j \leq j_{c}$, equation (10) is written taking into account the boundary conditions (12). In section 1, for a certain grid step $j\left(1 \leq j \leq j_{c}\right)$, the system of equations (10) compiled for $1 \leq i \leq i_{c}$ is written in vector form:

$$
\boldsymbol{T}_{j+1}+B_{j} \cdot \boldsymbol{T}_{j}+\boldsymbol{T}_{j-1}=\boldsymbol{F}_{j},\left(1 \leq j \leq j_{c}\right)
$$

where $\boldsymbol{T}_{j}\left[1: i_{c}\right]$ - a vector whose components are grid functions $T_{i, j}\left(1 \leq i \leq i_{c}\right) ; B_{j}\left[1: i_{c}, 1: i_{c}\right]$ - three-diagonal matrix containing the coefficients of equations $(10) ; \boldsymbol{F}_{j}\left[1: i_{c}\right]$ - vector whose components are the right-hand sides of the above equations.

The system of vector equations (18) is solved by the matrix sweep method. For this, a linear ratio of the boundaries by neighboring vectors $\boldsymbol{T}_{j-1}$ and $\boldsymbol{T}_{j}$ is compiled. For section 1 , this ratio is:

$$
\boldsymbol{T}_{j-1}=P_{j-1} \cdot \boldsymbol{T}_{j}+\boldsymbol{Q}_{j-1} .
$$

Matrices $P_{j}\left[1: i_{c}, 1: i_{c}\right]$ and vectors $\boldsymbol{Q}_{j}\left[1: i_{c}\right]$ are to be determined from the system of vector equations (18). For 
this, expression (19) is substituted into equation (18), which is solved with respect to $\boldsymbol{T}_{j}$ :

$$
\boldsymbol{T}_{j}=-\left(B_{j}+P_{j-1}\right)^{-1} \cdot \boldsymbol{T}_{j+1}+\left(B_{j}+P_{j-1}\right)^{-1} \cdot\left(\boldsymbol{F}_{j}-\boldsymbol{Q}_{j-1}\right) .
$$

Comparison of expressions (20) and (19) implies the relations:

$$
\begin{aligned}
& P_{j}=-\left(B_{j}+P_{j-1}\right)^{-1}, \\
& \boldsymbol{Q}_{j}=\left(B_{j}+P_{j-1}\right)^{-1} \cdot\left(\boldsymbol{F}_{j}-\boldsymbol{Q}_{j-1}\right) .
\end{aligned}
$$

The system of difference equations (10) for sections 2 and $3\left(j \geq j_{c}+1\right)$ is generalized by the vector equation:

$$
\boldsymbol{T}_{j+1}+B_{j} \cdot \boldsymbol{T}_{j}+\boldsymbol{T}_{j-1}=\boldsymbol{F}_{j},\left(j_{c}+1 \leq j \leq M\right),
$$

where $B_{j}[1: M, 1: M]$ - three-diagonal matrix containing the coefficients of the corresponding difference equations.

For nodes with numbers $j=j_{c}+1, i_{c}+1 \leq i \leq M$, which belong to the region of the fin and are closer to its heat transfer surface, the finite-difference equation of heat conduction (10) is supplemented by condition (17), which in vector form has view:

$$
\boldsymbol{T}_{j_{c}}=-\boldsymbol{T}_{j_{c}+1}+2 \boldsymbol{T}_{w}
$$

The vector $\boldsymbol{T}_{w}$ contains unknown values of the temperature on the surface of the fin.

For nodes with numbers $j=j_{c}+1,1 \leq i \leq i_{c}$, the linear relationship between adjacent vectors $\boldsymbol{T}_{j_{c}}$ and $\boldsymbol{T}_{j_{c}+1}$, used for section 1, has the form:

$$
\boldsymbol{T}_{j_{c}}=P_{j_{c}} \cdot \boldsymbol{T}_{j_{c}+1}+\boldsymbol{Q}_{j_{c}}
$$

The matrix $P_{j_{c}}\left[1: i_{c}, 1: i_{c}\right]$ and the vector $\boldsymbol{Q}_{j_{c}}\left[1: i_{c}\right]$ were determined by solving the vector equation (18) in section 1. To generalize expressions (24) and (25) for nodes with numbers $j=j_{c}+1 ; 1 \leq i \leq M$ consists of a vector relation:

$$
\boldsymbol{T}_{j_{c}}=P_{j_{c}}^{*} \cdot \boldsymbol{T}_{j_{c}+1}+\boldsymbol{Q}_{j_{c}}^{*}+R_{j_{c}}^{*} \cdot \boldsymbol{T}_{w}^{*}
$$

in which the matrix $P_{j_{c}}^{*}[1: M, 1: M]$ in rows with numbers $1 \leq i \leq i_{c}$ and columns with numbers $1 \leq i_{1} \leq i_{c}$ contains the elements of the matrix $P_{j_{c}}\left[1: i_{c}, 1: i_{c}\right]$. Vector $\boldsymbol{Q}_{j_{c}}^{*}[1: M]$ contains vector elements $\boldsymbol{Q}_{j_{c}}$ for $1 \leq i \leq i_{c}$. The matrix $R_{j_{c}}^{*}[1: M, 1: M]$ contains elements equal to zero, except for diagonal elements with numbers $i_{c}+1 \leq i \leq M$, the values of which are equa $R_{j_{c}, i,}^{*}=2$. $i_{c}+1 \leq i \leq M$ elements of the vector $\boldsymbol{T}_{w}^{*}\left[i_{c}+1: M\right]$ correspond to the unknown value of the temperature on the surface of the fin.

It is assumed that for $j \geq j_{c}+2$ the relation between vectors $\boldsymbol{T}_{j-1}$ and $\boldsymbol{T}_{j}$ has a form similar to expression (26), that is:

$$
\boldsymbol{T}_{j-1}=P_{j-1} \cdot \boldsymbol{T}_{j}+\boldsymbol{Q}_{j-1}+R_{j-1} \cdot \boldsymbol{T}_{w}^{*} .
$$

Substitution of expression (27) into vector equation (23) leads to an equation of the form:

$$
\boldsymbol{T}_{j+1}+B_{j} \cdot \boldsymbol{T}_{j}+P_{j-1} \cdot \boldsymbol{T}_{j}+\boldsymbol{Q}_{j-1}+R_{j-1} \cdot \boldsymbol{T}_{w}^{*}=\boldsymbol{F}_{j}
$$

from which the vector $\boldsymbol{T}_{j}$ is determined:

$$
\begin{aligned}
& \boldsymbol{T}_{j}=-\left(B_{j}+P_{j-1}\right)^{-1} \cdot \boldsymbol{T}_{j+1}+\left(B_{j}+P_{j-1}\right)^{-1} \cdot\left(\boldsymbol{F}_{j}-\boldsymbol{Q}_{j-1}\right)- \\
& -\left(B_{j}+P_{j-1}\right)^{-1} \cdot R_{j-1} \cdot \boldsymbol{T}_{w}^{*} .
\end{aligned}
$$

The following recurrence relations follow from the last expression:

$$
\begin{aligned}
& P_{j}=-\left(B_{j}+P_{j-1}\right)^{-1}, \\
& \boldsymbol{Q}_{j}=\left(B_{j}+P_{j-1}\right)^{-1} \cdot\left(\boldsymbol{F}_{j}-\boldsymbol{Q}_{j-1}\right), \\
& R_{j}=-\left(B_{j}+P_{j-1}\right)^{-1} \cdot R_{j-1},
\end{aligned}
$$

For $j_{c}+1 \leq j \leq N$.

The above ratios are used to calculate matrices $P_{j}, R$ and vectors $\boldsymbol{Q}_{j}$ for $j=j_{c}+1 \ldots N$. After their calculation, according to expression (27), compiled for $j=N$, the vector $\boldsymbol{T}_{N+1}$ is determined. For this, the boundary condition (15) is used, which in vector form has the form $\boldsymbol{T}_{N+1}=\boldsymbol{T}_{N}$. By expression:

$$
\boldsymbol{T}_{N+1}=P_{N} \cdot \boldsymbol{T}_{N+1}+\boldsymbol{Q}_{N}+R_{N} \cdot \boldsymbol{T}_{w}^{*}
$$

It follows:

$$
\boldsymbol{T}_{N+1}=\left(E-P_{N}\right)^{-1} \cdot \boldsymbol{Q}_{N}+\left(E-P_{N}\right)^{-1} \cdot R_{N} \cdot \boldsymbol{T}_{w}^{*},
$$

where $E$ - identity matrix. The last expression is written as:

$$
\boldsymbol{T}_{N+1}=Z+D \cdot \boldsymbol{T}_{w}^{*},
$$

The components of the vector $\boldsymbol{T}_{N+1}$ with numbers $i_{c}+1 \leq i \leq M$ correspond to the values $T_{\text {exp }, i}$ that were found from the experiment. The unknown components of the vector $\boldsymbol{T}_{N+1}$ are numbered as $1 \leq i \leq i_{c}$. The components of the vector $\boldsymbol{T}_{w}^{*}$ with numbers $i_{c}+1 \leq i \leq M$ are unknown quantities to be determined, and its components with numbers $1 \leq i \leq i_{c}$ have zero values. Thus, unknown quantities are contained partly in the vector $\boldsymbol{T}_{N+1}\left(1 \leq i \leq i_{c}\right)$ and partly in the vector $\boldsymbol{T}_{w}^{*}\left(i_{c}+1 \leq i \leq M\right)$.

After determining the vectors $\boldsymbol{T}_{N+1}$ and $\boldsymbol{T}_{w}^{*}$, using relation (27), vectors $\boldsymbol{T}_{j}[1: M]$ for $j=N \ldots j_{c}$ are consistently develop. The components of the vector $\boldsymbol{T}_{j_{c}}$ with numbers $1 \leq i \leq i_{c}$ corresponding to the temperature values at the grid nodes belonging to the region of wall 1 and are located closer to the boundary of section 3 (under the fin). A vector $\boldsymbol{T}_{j_{c}}$ is formed from these values, which has the dimension $\left[1: i_{c}\right]$. It is used for sequential calculation by expression (25) of vectors $\boldsymbol{T}_{j}$ (from $j=j_{c}-1$ to $j=1$ ) containing temperatures at the nodes of the wall.

The components of the vector $\boldsymbol{T}_{j_{c}}$ with numbers $i_{c}+1 \leq i \leq M$ corresponding to the temperature values at additional grid nodes, going beyond the computational domain and located closer to the heat transfer surface of the fin from the side of the coolant. These values are used to determine the heat transfer coefficient at the heat transfer surface of the fin. 
For this purpose, expression (8), describes the conditions for heat transfer from the surface of the fin to the coolant, is written in finite-difference form:

$$
\lambda \frac{T_{i, j_{c}+1}-T_{i, j_{c}}}{h_{x}}=\alpha_{p, i}\left(\frac{T_{i, j_{c}+1}+T_{i, j_{c}}}{2}-T_{\infty}\right),
$$

from which the expression follows:

$$
\alpha_{p, i}=\frac{2 \lambda\left(T_{i, j_{c}+1}-T_{i, j_{c}}\right)}{h_{x}\left(T_{i, j_{c}+1}+T_{i, j_{c}}-2 T_{\infty}\right)} .
$$

After calculating the temperatures at the grid nodes, the distribution of the heat transfer coefficients over the fin surface for $i_{c}+1 \leq i \leq M$ is determined by relation (32).

\section{Research results and discussion}

Using this algorithm, the distribution of heat transfer coefficients over the surface of the fin is determined; it is an element of a copper finned wall $(\lambda=381 \mathrm{~W} /(\mathrm{mK}))$ with geometric dimensions $L=1.5 \mathrm{~mm} ; \delta_{p}=1.0 \mathrm{~mm} ; \delta_{c}=5.0 \mathrm{~mm}$; $h=22.0 \mathrm{~mm}$. Let's consider the cases of the densities of the heat flux supplied to the wall $q_{f}=481.056 \mathrm{~kW} / \mathrm{m}^{2}$ and $q_{f}=601.056 \mathrm{~kW} / \mathrm{m}^{2}$. The temperature distributions along the fin axis, found from the experiment, are shown as discrete points in Fig. 4. This figure also shows the approximation curves of the temperature distribution along the fin axis $t_{\exp }(y)$, used for the numerical solution of the problem. The heat transfer coefficient on the fin surface is determined from expression (32), which contains the temperature of the coolant $t_{\infty}$. In the interfin space, the temperature of the liquid in which heat transfer from the surface of the fin and wall occurs can vary from its value at the entrance to the experimental section $t_{0}$ to the saturation temperature $t_{\text {sut }}$. The temperature $t_{0}$ is determined by the conditions of the experiment, but $t_{\text {sut }}$ depends on the pressure distribution over the channel of the experimental section. Experimental studies were carried out under conditions $t_{0}=100^{\circ} \mathrm{C}$. It is also determined that $t_{\text {sut }} \sim 140{ }^{\circ} \mathrm{C}$. From the data shown in Fig. 4, it follows that the observed temperature values on the fin axis are both higher than $t_{\text {sut }}$ and lower than $t_{\text {sut }}$. That is, the boiling of the liquid does not occur on the entire surface of the fin, but only on that part of it, the temperature of which exceeds $t_{\text {sut }}$.

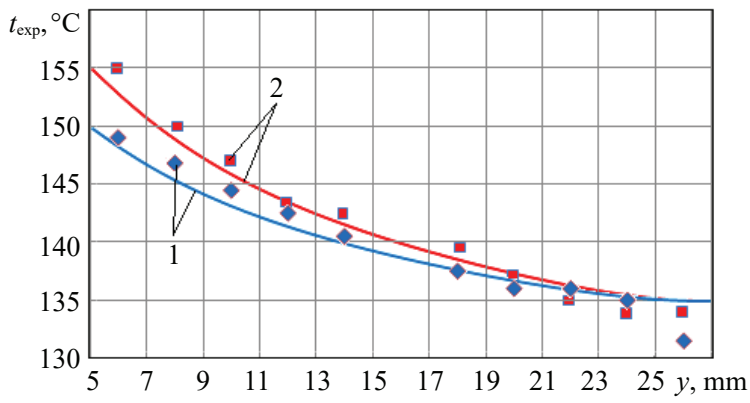

Fig. 4. Temperature distribution along the fin axis: $1-q_{f}=481.056 \mathrm{~kW} / \mathrm{m}^{2} ; 2-q_{f}=601.056 \mathrm{~kW} / \mathrm{m}^{2}$

○, - experimental points; $\stackrel{2}{=}$ - approximation curves

To determine the heat transfer coefficient $\alpha$, it is assumed that $t_{\infty}=t_{0}=100{ }^{\circ} \mathrm{C}$. The distributions of the heat transfer coefficients over the fin surface for the two considered cases of the heat flux density $q_{f}$ are shown in Fig. 5.

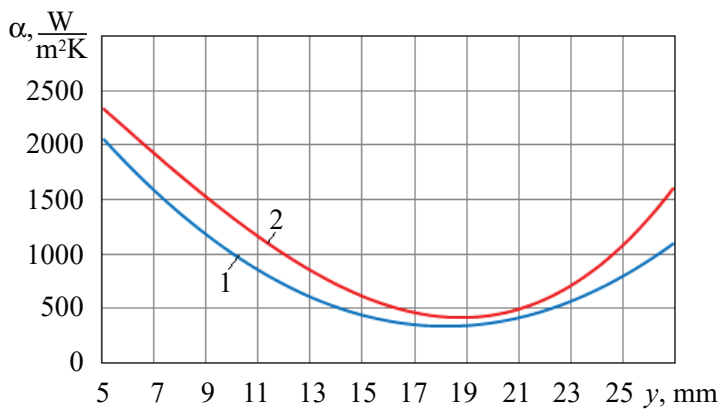

Fig. 5. Distribution of heat transfer coefficients over the fin surface: $1-q_{f}=481.056 \mathrm{~kW} / \mathrm{m}^{2} ; 2-q_{f}=601.056 \mathrm{~kW} / \mathrm{m}^{2}$

From Fig. 5 it can be seen that the maximum values of the heat transfer coefficients correspond to the section of the fin located directly at the surface of the wall. Their values decrease along the $0 Y$ axis. After reaching the minimum values, the heat transfer coefficients along the surface of the fin begin to grow. The maximum values of the heat transfer coefficient at the base of the fin $\left(y=\delta_{c}=5.0 \mathrm{~mm}\right)$ are $\alpha=2053 \mathrm{~W} /\left(\mathrm{m}^{2} \cdot \mathrm{K}\right)$ for the case of $q_{f}=481.056 \mathrm{~kW} / \mathrm{m}^{2}$ and $\alpha=2330 \mathrm{~W} /\left(\mathrm{m}^{2} \cdot \mathrm{K}\right)$ for the case of $q_{p}=601.056 \mathrm{~kW} / \mathrm{m}^{2}$. Their minimum values for the first case are $\alpha=338 \mathrm{~W} /\left(\mathrm{m}^{2} \cdot \mathrm{K}\right)$ at $y=18.1 \mathrm{~mm}$, and for the second case $-\alpha=414 \mathrm{~W} /\left(\mathrm{m}^{2} \cdot \mathrm{K}\right)$ at $y=18.7 \mathrm{~mm}$. At $y=y_{\max }=27 \mathrm{~mm}$, the values of the heat transfer coefficients increase to $\alpha=1095 \mathrm{~W} /\left(\mathrm{m}^{2} \cdot \mathrm{K}\right)$ in the first case and to $\alpha=1600 \mathrm{~W} /\left(\mathrm{m}^{2} \cdot \mathrm{K}\right)$ in the second case.

This character of the change in the heat transfer coefficient along the surface of the fin is explained by the fact that the liquid boils in the part of the surface where its temperature exceeds the saturation temperature $t_{\text {sut }}$. In this case, along the surface of the fin, the value $\vartheta$ decreases. According to dependencies (1), the heat transfer coefficient also decreases. On the section of the fin surface where $t_{w}<t_{\text {sut }}$ boiling does not occur and heat transfer to the coolant occurs due to forced and natural convection. With longitudinal liquid flow around the finned surface, in the intercostal space, which is located closer to the end surfaces of the fins, a vortex flow is formed due to the separation of the external flow from the ends. This contributes to the intensification of heat transfer in this area of the fin surface. As a result, after the heat transfer coefficients reach their minimum values, their values begin to grow in the direction of the $0 Y$ axis.

\section{Conclusions}

In the course of the work, a new method was developed for determining the distribution of heat transfer coefficients over the surface of a fin during boiling of water on a finned wall and an algorithm for solving the inverse problem of heat conduction. This algorithm is based on using the finite difference method and matrix sweep to solve a system of finite difference equations. This can be used to determine the distribution of heat transfer coefficients over the surface of the fin according to experimental data on the temperature distribution along the axis of the fin. The distribution of heat transfer coefficients over the surface of the fin, on which various modes of boiling of the liquid 
can exist, determined by the proposed method, indicates the unevenness of this distribution. The maximum values of the heat transfer coefficients are observed at the base of the fin, where the temperature of the heat transfer surface $t_{w}$ most significantly exceeds the saturation temperature $t_{\text {sut }}$. In the direction of the $0 Y$ axis, the temperature of the fin surface decreases, which also causes a decrease in the heat transfer coefficient. After reaching the minimum values, the heat transfer coefficients in the direction of the $0 Y$ axis begin to grow, which is associated with the effect of separation of the external coolant flow from the end surface of the fin and the formation of a vortex flow in the upper section of the interfin space. To determine the heat transfer coefficients on the finned surface during liquid boiling, it is not enough to apply only expressions (1), taking into account only the value of the temperature head $\vartheta=t_{w}-t_{\text {sut }}$. Their values also depend on the hydrodynamic conditions of the external coolant flow around the finned surface.

\section{References}

1. Haley, K. W., Westwater, J. W. (1966). Boiling heat transfer from single fins. Proceedings of the Third International Heat Transfer Conference AJChE - ASME, 3, 245-253. doi: https:// doi.org/10.1615/ihtc3.300

2. Kovalev, S. A., Smirnova, L. F. (1968). O temperaturnom pole rebra, omyvaemogo kipiaschei zhidkostiu. Teplofizika vysokikh temperatur, 4 (6), 698-701.

3. Dulkin, I. N., Rakushina, N. I., Roizen, L. I., Fastovskii, V. G. (1970). Teploobmen pri kipenii vody i freona-113 na neizotermicheskoi poverkhnosti. Inzhenerno-fizicheskii zhurnal, 19 (4), 637-645.

4. Rubin, I. R., Dulkin, I. N., Roizen, L. I. (1978). Teploobmen pri kipenii zhidkosti na poverkhnosti koltsevogo rebra postoiannoi tolschiny. Teplofizika vysokikh temperatur, 16 (2), 365-369.
5. Roizen, L. I., Evteev, B. N., Dulkin, I. N. (1970). Raschet teploperedachi v priamougolnom rebre. Elektronnaia tekhnika. Seriia I. Elektronika SVCH, 7, 81-84.

6. Kern, D., Kraus, A. (1977). Razvitye poverkhnosti teploobmena. Moscow: Energiia, 464.

7. Bosyi, V. V., Marynenko, V. I. (1996). Modeliuvannia teplovykh rezhymiv reber pry riznykh umovakh teploobminu. Kyiv: Ministerstvo osvity Ukrainy, 116.

8. Zverev, V. G., Nazarenko, V. A., Panko, S. V., Teploukhov, A. V. (2010). Opredelenie parametrov konvektivnogo teploobmena po izmereniiam temperatury materiala. Teplofizika vysokikh temperatur, 48 (5), 779-784.

9. Formalev, V. F., Kolesnik, S. A. (2013). A methodology for solving inverse coefficient problems of determining nonlinear thermophysical characteristics of anisotropic bodies. High Temperature, 51 (6), 875-883. doi: http://doi.org/10.7868/ s0040364413050062

10. Marynenko, V. I., Davydenko, B. V. (2002). Metodyka vyznachennia koefitsiienta teploviddachi na orebrenii stintsi. Enerhetyka: ekonomika, tekhnolohii, ekolohiia, 1, 40-44.

11. Marinenko, V. I., Davydenko, B. V. (2002). Opredelenie koeffitsienta teplootdachi na orebrennoi stenke. Energetika $i$ elektrotekhnika, 3, 40-42.

Marinenko Vladimir, PhD, Associate Professor, Department of Nuclear Power Stations and Engineering Thermophysics, National Technical University of Ukraine «Igor Sikorsky Kyiv Polytechnic Institute»,Ukraine, e-mail: v.marinenko@gmail.com, ORCID: http:// orcid.org/0000-0002-8789-3432

Davydenko Boris, Doctor of Technical Science, Chief Researcher, Department of Thermophysical Basics of Energy-Saving Technologies, Institute of Engineering Thermophysics of National Academy of Sciences of Ukraine, Kyiv, Ukraine, e-mail: bdavydenko@ukr.net, ORCID: http://orcid.org/0000-0001-8738-7612 